Estudios sobre el Mensaje Periodístico ISSN-e: 1988-2696

http://dx.doi.org/10.5209/ESMP.55605

\title{
Las narrativas del ataque contra Charlie Hebdo. Un estudio de la cobertura periodística internacional
}

\author{
Pablo Gómez-Domínguez'; Gabriel Candelaria Rivera²; Oliver Pérez Latorre ${ }^{3}$; Lorena \\ Gómez-Puertas ${ }^{4}$
}

Resumen. Este estudio se propone como objetivo general analizar comparativamente la cobertura en portada del ataque a Charlie Hebdo (2015) en los periódicos de mayor tirada de Francia, Estados Unidos, Suecia, Turquía, Emiratos Árabes Unidos y Argelia. Para ello se aplica una metodología mixta que combina el análisis de contenido cuantitativo con el análisis semiótico narrativo y un frame-analysis inductivo. Los resultados revelan diferencias significativas entre países en cuanto a cobertura formal, texto e imagen, y permiten detectar dos grandes programas narrativos. Por un lado, el que reivindica la inocencia de la comunidad musulmana y culpabiliza a los líderes políticos occidentales y árabes, correspondiente a Argelia. Y por otro, el relato liderado por Francia, que incide en el empoderamiento social y el apoyo gubernamental para defender la libertad de expresión y se impone como hegemónico en Occidente.

Palabras clave: Charlie Hebdo; semiótica; análisis de contenido; Francia; Argelia.

\section{[en] The narratives of Charlie Hebdo's attack. A cross-national study of the news coverage}

\begin{abstract}
This study proposes an analysis of the front pages in the coverage of the attack on Charlie Hebdo in major newspapers in France, USA, Sweden, Turkey, United Arab Emirates and Algeria. We applied a mixed methodology that combines quantitative/qualitative content analysis, semiotic analysis and frame-inductive analysis. The results show significant differences between countries in terms of formal coverage, presence and distribution of text and image. In addition, we found two great narrative programs. The Algerian, claiming the innocence of the Muslim community and blames Western and Arab political leaders. And the French, with a program alluding to social empowerment and government support to defend freedom of speech. As the general conclusion, the widely shared story was the French's Western-imposed over the Algerian-Arabic narrative.
\end{abstract}

Keywords: Charlie Hebdo; semiotics; content analysis; France; Algeria.

Sumario. 1. Introducción. 2. Marco teórico. 3. Objetivos. 4. Metodología; 4.1. Corpus. 4.2; Aplicación. 5. Resultados; 5.1. Las portadas internacionales del caso Charlie Hebdo; 5.2. Las estrategias narrativas; 5.2.1. Itinerarios; 5.2.2. Programa narrativo y modelo actancial; 5.2.3.

1 Universitat Pompeu Fabra.

E-mail: pablo.gomez@upf.edu

2 Universidad de de Puerto Rico.

E-mail: gcandelaria@gmail.com

3 Universitat Pompeu Fabra

E-mail: oliver.perez@upf.edu

4 Universitat Pompeu Fabra.

E-mail: lorena.gomez@upf.edu 
Perspectivas axiológicas; 5.3. Aportación metodológica: taxonomía de encuadres narrativos. 6 . Conclusión y discusión. 7. Referencias bibliográficas. 8. Conflictos de interés. 9. Agradecimientos.

Cómo citar: Gómez-Domínguez, Pablo; Candelaria Rivera, Gabriel; Pérez Latorre, Oliver; y GómezPuertas, Lorena (2017): "Las narrativas del ataque contra Charlie Hebdo. Un estudio de la cobertura periodística internacional”, en Estudios sobre el Mensaje Periodístico 23 (1), 417-436.

\section{Introducción}

Charlie Hebdo es una revista satírica francesa que se inicia en 1969 con ediciones mensuales bajo el nombre de Charlie. El año 1981 cesan sus publicaciones por falta de ingresos y se renueva en 1992 con frecuencia semanal y su actual cabecera Charlie Hebdo.

El semanario se autodefine ideológicamente de izquierda y en sus contenidos apuesta por la crítica social y política de sucesos de actualidad. Han dedicado diversas ediciones a la religión cristiana, judía y musulmana con caricaturas sobre sus líderes espirituales. El año 2006 supuso un punto de inflexión para la publicación al reponer y ampliar caricaturas de Mahoma que el semanario danés Jyllans Posten había difundido originalmente. Estas caricaturas provocaron reacciones de diversa índole a nivel internacional entre líderes políticos y religiosos, y diversos colectivos sociales. El debate giró en torno a los límites entre humor y libertad de expresión. Desde este momento, la revista se convierte en un referente del laicismo francés y de los valores de libertad (de expresión) de la República.

También esta línea editorial es la que ha convertido al semanario en blanco de diversos ataques y objetivo señalado para organizaciones terroristas como Al-Qaeda o Estado Islámico. El año 2011 su sede de Paris sufrió un primer atentado con cóctel molotov, que llevó a Charlie Hebdo mantener con mayor tesón su postura crítica. Así, su editor, Stephane Charbonnier, lo declaraba en 2012, al referirse a la presión que sufría la revista para que cesara las publicaciones sobre Mahona: "I have no kids, no wife, no car, no credit. [...] but I prefer to die standing than living on my knees". En un segundo atentado, un tiroteo en la sede de la revista en París a manos de los hermanos Kouachi, dos franceses de origen argelino, el 7 de enero de 2015 murieron 5 trabajadores, entre ellos Charbonnier, y otras 7 personas. El atentado fue reivindicado por la célula yemení de Al-Qaeda y contestado firmemente por diversas concentraciones espontáneas en Francia esa misma noche bajo un lema compartido por toda Europa a través de las redes sociales, "Je Suis Charlie", en apoyo a la revista y a la libertad de expresión.

El atentado no sólo conllevó una amplia movilización ciudadana sino también el despliegue de las fuerzas armadas en Francia. Durante los días sucesivos se produjeron diversos ataques contra la comunidad musulmana francesa en la mezquita de Le Mans y en un lugar de culto en Port-La-Nouvelle, intensificadas tras un segundo ataque contra una tienda judía en la zona de Vincennes el 10 de enero. En el ámbito institucional, François Hollande dirigió una marcha multitudinaria junto a líderes de 44 países el 11 de enero en París, como escenificación sin precedentes de la reivindicación de la libertad de expresión y el rechazo al terrorismo en Occidente.

Estos sucesos repercuten sobre la percepción de seguridad ante el terrorismo de la sociedad francesa y europea, y convierten a Charlie Hebdo en un símbolo de la libertad de expresión, innegociable para las democracias modernas. El sentimiento 
general quedó resumido en las palabras de Martin Schulz, Presidente del Parlamento Europeo: "These cartoonist, these journalists, these policemen, these employees, these jewish citizens died because they defend and they embodied whats fanatics do not want: Criticism, Humor, Satire, Freedom of expression"'5.

Este hecho ofrece pues una oportunidad única para observar las posturas, sobre las causas y las consecuencias de estos atentados, dentro y fuera de Europa. En esta línea trabaja Wolska-Zogata (2015) al analizar un período de cobertura amplio, entre el 7 de enero y el 22 de febrero, si bien en una comparativa reducida a diarios de Estados Unidos, Francia y Reino Unido, a partir del framing analysis apoyado sobre la narratología. Por ello, la finalidad de esta investigación es realizar un estudio comparativo con una muestra internacional que sobrepase el eje occidental y nos permita comprobar cómo se desarrolló la cobertura periodística del ataque a Charlie Hebdo a nivel mundial, con especial énfasis en la creación de programas narrativos y la configuración de dos conceptos-valores binarios alrededor de ellos: libertad y terrorismo.

\section{Marco teórico}

Este estudio se estructura a partir de diversas perspectivas teóricas asociadas al establecimiento de la agenda, el análisis semiótico narrativo y, por último, el encuadre noticioso o news-frame.

La teoría de la agenda setting (McCombs, 2004) es útil para plantear cómo los medios de comunicación jerarquizan y estructuran el contenido para otorgar mayor relevancia a unas cuestiones sobre otras. Esto pone en evidencia las preferencias del medio ante sujetos o conceptos específicos. Rogel y Cabrera 2013: 238) apuntan que el establecimiento de la agenda mediática influye irremediablemente en la agenda social ya que "muchos de los temas seleccionados [por el medio] también son los considerados de mayor importancia por la sociedad". Del mismo modo, Cáceres (2011: 304) trata la importancia que tiene la cobertura mediática en la problematización o en la omisión de un hecho pues "aquello que carece de visibilidad pública no tiene existencia".

La perspectiva de la agenda-setting es esencial para estudiar la comunicación de crisis y el tratamiento de conflictos culturales y religiosos. En el primer caso, Kasset y Mustaffa (2014) estudian la cobertura de la Guerra de Irak por parte de dos periódicos de lengua inglesa en Malasia. Los autores concluyeron que existía una polarización en la agenda temática de ambos periódicos. Uno de ellos priorizaba los efectos negativos del conflicto sobre Irak y el otro sus posibles consecuencias para Malasia. En el caso de la representación cultural de comunidades religiosas, Amara (2013) investiga la cobertura mediática del Islam en medios de comunicación franceses. El autor determina que los medios de comunicación penalizan las expresiones públicas de esta religión, tendiendo a minimizar su presencia en la agenda pública. Dolezal, Helbling y Hutter (2010) analizan la exposición mediática de comunidades musulmanas en Austria, Suiza y Alemania antes y después del 11 de septiembre de 2001. Sus resultados remarcan el protagonismo de los

Consúltese en:

http://www.europarl.europa.eu/the-president/en/press/press_release_speeches/speeches/speeches-2015/speeches-2015-january/html/minute-of-silence-for-the-victims-of-the-attacks-against-the-charlie-hebdo-magazinefrance-s-police-forces-and-the-jewish-supermarket;jsessionid=604A35A0E90E89E039EAB52C003C3294 
medios de comunicación en la mediación, a través de sus agendas, entre esta comunidad religiosa y el resto de la sociedad.

A nivel narrativo, la semiótica nos ofrece la oportunidad de conocer los relatos que conviven en la cobertura mediática. El modelo actancial de Greimas y Courtés (1982) supone una aportación teórica y metodología para examinar estos relatos, identificar la estructura discursiva, la distribución de roles (actantes) narrativos y el conjunto de valores que transmite el texto. Este modelo se compone de cuatro elementos en lo que Greimas (2007) bautizó como esquema narrativo canónico:

1. El contrato: fase en la que un destinador propone o encarga a un sujeto de estado/destinatario una tarea o un conjunto de tareas concretas. A esta fase puede precederla una de desajuste.

2. La competencia: cualidad/es que posee o adquiere el sujeto para realizar la tarea que se le ha encomendado.

3. La prueba o performance: resolución de la tarea.

4. Sanción: conjunto de recompensas o castigos que obtiene el sujeto al resolver/ cumplir la tarea/s encomendada/s.

Dentro de este esquema narrativo intervienen una serie de sujetos o, como los denomina Greimas, actantes cuya significación en el esquema narrativo cabe aclarar. Estos actantes son:

- El Destinador (D): encarga la tarea.

- Sujeto de estado/destinatario (DT): recibe el encargo del destinador.

- Sujeto de acción (SA): lleva a cabo la tarea y puede coincidir o no con el sujeto de estado.

— Objeto de deseo (OD): objetivo final del sujeto de acción al llevar a cabo su tarea.

- Ayudante (AY): sujeto/s o elementos que colaboran en la consecución de la tarea.

- Oponente/anti-sujeto (OP): sujeto/s o elementos que obstaculizan la consecución de la tarea.

Este modelo tiene múltiples aplicaciones, siendo antecedentes a considerar en nuestro estudio, el análisis de la cobertura del conflicto de Kosovo realizada por El País de Penalva y Mateo (2000: 2), para quienes "[este análisis] no sirve solamente para ayudar a acceder al significado contenido en el esquema narrativo, sino también para detectar las implicaciones en cuanto a efectos ideológicos". Entre sus resultados, resalta la detección de programas narrativos recurrentes a lo largo del conflicto y la evolución en la distribución de roles/actantes entre los diferentes países implicados. Ruiz-Collantes et al. (2011) examinan, mediante la semiótica, la representación de los inmigrantes en series de ficción televisiva española. Los autores localizan roles recurrentes en los que los inmigrantes cumplían la función narrativa de: embaucadores, al margen de la ley y oportunistas. Unos papeles que se traducían, a través del relato televisivo, en una imagen real negativizada de este colectivo.

Por último, el estudio del encuadre mediático o de news frame cuyos orígenes se remontan a propuestas teóricas vinculadas a la antropología ${ }^{6}$, la sociología y los estudios

6 Gregory Bateson será quien acuñe el término encuadre en el año 1955. 
de comunicación, completa el diseño metodológico. El encuadre como un marco de referencia construido y compartido por los individuos en su dimensión social (Goffman, 1974), es desarrollado por Tuchman (1978) como encuadre noticioso que determina, mediante un enfoque interno, la elaboración de las noticias desde las redacciones periodísticas (framing). Entman (1991) contextualiza el desarrollo del encuadre dentro de un proceso amplio de selección, procesamiento y emisión final de la información que se enmarca en una cultura determinada y una década después, Tankard (2001) concluye que los medios realizan una selección intencionada de ciertos aspectos de la realidad para que sus consumidores generen interpretaciones condicionadas de los hechos noticiables.

En cuanto a las aplicaciones precedentes, son de nuestro interés las aportaciones de autores como De Vreese et al. (2001) que estudian la construcción periodística mediante técnicas de framing al tratar la entrada en vigor de la moneda única en la Unión Europea, y detectan un encuadre mayoritario centrado en las consecuencias económicas para los países que adopten el euro. O bien, trabajos como el de Reese (2010) sobre la War on Terror de la administración Bush, en el que se detectan dos encuadres principales de signo opuesto: el "war frame" que enfatizaba las ventajas de una actuación militar y el "diplomacy frame" que acentuaba la importancia de intensificar las actuaciones políticas para evitar el conflicto.

\section{Objetivos}

La revisión teórica nos permite establecer como objetivo general examinar las portadas de los dos diarios de máxima tirada en Estados Unidos, Francia, Suecia, Emiratos Árabes Unidos, Argelia y Turquía para desvelar las estrategias narrativas de su cobertura mediática. Este objetivo general se concreta en los siguientes objetivos específicos:

- Analizar la estructura formal, elementos textuales y visuales, de cada portada para detectar diferencias significativas entre las publicaciones.

- Explorar los itinerarios cronológicos y la estructura narrativa de las noticias sobre el ataque a Charlie Hebdo para identificar y elaborar el modelo actancial de cada diario.

- Desarrollar los esquemas axiológicos a partir de los programas narrativos con la finalidad de observar la distribución de valores entre países.

- Proponer una clasificación de encuadres narrativos específicos que aglutinen los programas narrativos y los aspectos formales de la cobertura para comprobar su distribución temporal en cada publicación.

\section{Metodología}

\subsection{Corpus}

La muestra de países y publicaciones sigue una composición de estudio de caso múltiple (Yin, 2009). Se seleccionan 6 países y, dentro de ellos, las dos publicaciones 
de prensa escrita con mayor tirada ${ }^{7}$ siguiendo criterios geográficos, confesionales, políticos, de índice democrático ${ }^{8}$ y de lengua oficial.

Así, a nivel geográfico seleccionamos dos países europeos, uno euroasiático, uno norteamericano, uno de Oriente próximo y uno del norte de áfrica. En cuanto a sistema político, contamos con cuatro repúblicas, una monarquía parlamentaria y una monarquía constitucional. La distribución religiosa es igualmente diversa, dos países protestantes, uno de mayoría católica, y tres de confesión musulmana. El índice de democracia nos indica que tres de los países de la muestra se encuentran sobre el 7.88 (entre democracia plena y democracia defectuosa) y el resto no obtiene más del 5,76 (régimen híbrido y régimen autoritario). Por último, el corpus contempla cinco lenguas: inglés, francés, árabe, turco y sueco.

Cabe remarcar que Francia y Argelia tienen un criterio de selección añadido que está relacionado con su protagonismo en los atentados. Francia es el lugar en el que se producen los hechos mientras que Argelia es el país originario de la familia Kouachi a la que pertenecen los hermanos que atacaron Charlie Hebdo. A continuación, se muestra el listado de publicaciones analizadas en función del país de origen:

- Francia: Le Monde y Le Figaro

- Estados Unidos: USA Today y Wall Street Journal

- Suecia: Dagens Nhyter y Aftonbladet

- Turquía: Zaman y Posta

- Argelia: Echorouk y El Khabar

— Emiratos Árabes Unidos: Al Ittihad y Khaleej Times ${ }^{9}$

La muestra temporal es seleccionada según el criterio de acumulación en la cobertura mediática (news coverage) sobre el objeto de estudio, los días 8 y 12 de enero de $2015^{10}$. Esto garantiza la representatividad de los datos emitidos por cada medio. El día 8 de enero es el posterior al atentado y el 12 de enero es el día posterior a la manifestación multitudinaria en la Plaza de la República de Paris.

Finalmente, se analiza un total de 24 portadas y 46 unidades de análisis que incluyen imagen y/o texto de los 12 diarios seleccionados. La recolección de la información de estos diarios se llevó a cabo mediante las plataformas online de las publicaciones ${ }^{11}$. Se excluyó la versión web y tan solo se utilizaron las portadas originales impresas de cada periódico.

Dado el carácter internacional de esta investigación, fue necesario traducir las portadas en inglés, francés, árabe, turco y sueco por parte de asesores con dominio de estas lenguas y del castellano. Esta condición garantiza la fiabilidad de las traducciones para la aplicación de las técnicas que se explicitan en el siguiente apartado.

Consultados los organismos de auditoría de la difusión de los países que los poseen y, en su defecto, datos de difusión de otras fuentes.

8 Índice calculado por la Intelligence Unit de The Economist que tiene en cuenta más de 60 indicadores agrupados en proceso electoral y pluralismo, libertades civiles, funcionamiento del gobierno, participación política y cultura politica.

$9 \quad$ Diario editado en lengua inglesa.

10 Excepto en el caso de Le Monde pues su condición de diario vespertino hizo que tuviéramos que obtener la muestra los días 9 y 13 de enero de 2015.

11 Consúltese: http://www.echoroukonline.com/portal/, http://www.elkhabar.com/, http://www.zaman.com.tr/haber, http://www.posta.com.tr/, http://www.alittihad.ae/, http://www.khaleejtimes.com/index00.asp, http://www. lemonde.fr/, http://www.dn.se/, http://www.aftonbladet.se/, http://www.usatoday.com/y http://www.wsj.com/ 


\subsection{Aplicación}

El estudio de la cobertura periodística, de acuerdo a los referentes en el campo (Penalva y Mateo, 2000; Torregrosa, 2010; Visa, 2012; Konstantinidou, 2008) se desarrolla teniendo en cuenta los textos de portada que se corresponden con el título, el titular, el subtítulo, el sumario y el pie de foto, mediante la aplicación de la combinación de técnicas cuantitativas y cualitativas acordes a la metodología mixta expuesta más arriba. En cuanto a las imágenes, se contemplan todas las fotografías relacionadas con el ataque a Charlie Hebdo y se excluyen imágenes de tipo caricatura.

Sobre esta muestra se aplica un análisis de contenido para caracterizar la cobertura desde el punto de vista del país de procedencia, la publicación que produce las noticias y los elementos que la componen: imagen y texto (Riffe, Lacy y Fico, 2005; Krippendorff y Bock, 2009). Este análisis de contenido se acompañó de una matriz propia de 34 variables, con sus respectivas categorías, agrupadas en tres dimensiones: descriptiva, imagen y actores ${ }^{12}$.

Por otro lado, se lleva a cabo un análisis semiótico narrativo de la cobertura del ataque a Charlie Hebdo como un discurso periodístico del que es posible conocer su estructura superficial y profunda además del papel que juegan los actores que intervienen de forma recurrente en el relato. Para ello, el análisis se divide en tres fases: detección de itinerarios narrativos, que permite la identificación de la situación temporal de los relatos, esto es, en qué momento inicia la cobertura; la construcción de los modelos actanciales (Greimas y Courtés, 1982; Floch, 1993; Penalva y Mateo, 2000); y, por último, la detección de la estructura de valores o modelo axiológico subyacente (Smith et al., 2004; Konstantinidou, 2008; Karry, 2010).

Por último, empleamos un análisis inductivo de encuadres narrativos específicos para observar su frecuencia y distribución en la cobertura (Reese y Lewis, 2009; Marín, 2012). Según Reese (2010), a la hora de detectar encuadres específicos, existen múltiples ventajas en la aplicación de una metodología inductiva que se apoye en el análisis del discurso. Ruiz Collantes et al. (2011: 114) muestran como el análisis semiótico permite desvelar narraciones prototípicas compartidas en diferentes relatos de una muestra diversa que actúan como constructos o encuadres identificables de los acontecimientos noticiosos.

\section{Resultados}

\subsection{Las portadas internacionales del caso Charlie Hebdo}

Un análisis de la cobertura formal del ataque por parte de las publicaciones de la muestra nos acerca a la distribución de dos elementos esenciales: el texto y la imagen. Así, calculamos la frecuencia de noticias e imágenes en función del diario y la fecha de publicación. Esta comparación porcentual caracteriza la relevancia que otorgó cada diario, en términos formales, al atentado contra Charlie Hebdo.

Los porcentajes se distribuyen en tres fechas clave: el 7, el 11 y el 12 de enero de 2015. En cuanto a la distribución según la publicación, Echorouk y El Khabar de

12 La dimensión de datos descriptivos cuenta con variables como el número de portada analizada, el diario, la presencia o ausencia de imágenes o la posición del texto. Mientras que la dimensión de imagen agrupa variables como la fecha de la toma, el nombre atribuido, la fuente o el formato. Por último, la dimensión de actores codifica el tipo de actor, la relevancia, el cargo, el número o la acción desarrollada, entre otras variables. 
Argelia son los que dedican un mayor porcentaje de noticias al día en que se produce el ataque a la sede del semanario, un $8 \%$ y un $14 \%$ respectivamente. El diario turco Zaman dedica la tercera mayor proporción de noticias a este día con un 5\% del total. Sin embargo, existe un equilibrio porcentual entre las publicaciones, excepto en las argelinas, con una media del 3\% en el porcentaje de noticias para los días del atentado y la manifestación. Aun así, Le Figaro, USA Today y Aftonbladet destacan por dedicar un $8 \%, 5 \%$ y 5\% respectivamente a la manifestación en la Plaza de la República de Paris. Por último, USA Today es la única publicación que dedica un porcentaje de noticias al día después de la manifestación.

La frecuencia relativa de noticias necesita de otro indicador que complete el análisis de la cobertura. Por ello, acudimos al número de imágenes en función de la fecha y el diario. Los resultados muestran de nuevo que los diarios argelinos Echorouk y El Khabar poseen el porcentaje más amplio de imágenes para el día del atentado, con un $8 \%$ y un $14 \%$ respectivamente. Ese mismo día existe un equilibrio en el porcentaje de imágenes en el resto de diarios, aunque el turco Zaman ofrece una proporción superior a la media. Al igual que sucede las noticias, USA Today, Le Figaro y Aftonbladet dedican el porcentaje más alto de imágenes al día de la manifestación. En este caso no existe ninguna imagen asociada al día 12 de enero.

Para finalizar este apartado sobre la cobertura formal, resulta relevante ofrecer los datos sobre actores políticos y sociales representados en las imágenes de los diarios. Esto nos acerca a la jerarquización de ciertos personajes por encima de otros y, por lo tanto, al papel otorgado en la agenda mediática sobre el conflicto. Los actores sociales son priorizados en los periódicos de Suecia y Francia además del norteamericano USA Today con unos porcentajes que van desde el 45,45\% en Le Figaro hasta el 100\% en Le Monde, Aftonbladet, Dagens Nyheter y USA Today. Las imágenes que retratan terroristas, personal sanitario y/o de seguridad y actores políticos se concentran en los diarios argelinos Echorouk y El Khabar. En el caso de los terroristas, estos diarios poseen una media del 29,26\% en sus imágenes. Sin embargo, Al Ittihad y Kahleej Times de EAU tienen la distribución más equilibrada de actores sociales, terroristas y de seguridad, dejando sin representación visual a los actores políticos. Por último, los diarios Posta y Le Figaro además de los argelinos, son los únicos, con una media del $26 \%$ del total, en retratar a los terroristas sin la presencia de actores de las fuerzas de seguridad.

Los datos obtenidos mediante este análisis de contenido revelan diferencias significativas entre publicaciones a nivel de cobertura formal. Especialmente las publicaciones de Argelia destacan en cuanto a porcentaje de noticias, imágenes y distribución de actores. Se aprecia una división en la cobertura textual y visual en dos bloques bien diferenciados, uno argelino y otro formado por el resto países.

\subsection{Las estrategias narrativas}

\subsubsection{Itinerarios}

La distribución cronológica de los hechos que rodean el atentado a Charlie Hebdo nos informa sobre el comienzo del programa narrativo en cada uno de los países. Esta distribución incluye hechos que se remontan a los conflictos bélicos de Gaza, Siria e Irak y se extiende hasta los días posteriores al atentado y la manifestación.

Es relevante detectar dónde, cuándo y con quién comienza la línea temporal para comprender el relato que presenta cada una de las publicaciones. La cronología es, 
además, el reflejo de una narrativa compartida que sitúa, mediante los medios de comunicación, la cadena de sucesos en una relación de causa-efecto-consecuencia. Hemos desarrollado una ilustración (figura 1) que muestra los itinerarios cronológicos de cada país. Para ello, unificamos la distribución temporal de las publicaciones en una sola línea de tiempo. En total, en la figura 1, observaremos una línea para cada país que se distribuye antes, durante y después del atentado contra el semanario satírico. Esta figura 1 muestra dos itinerarios que podemos clasificar como opuestos entre dos bloques. Uno formado por Francia, Estados Unidos, EAU, Suecia y Turquía y otro tan sólo por Argelia. La cronología de los diarios franceses comienza el relato con el atentado a las Torres Gemelas el 11 de septiembre de 2001 mediante el titular de Le Monde "El 11 de septiembre francés". Continúa con la aprobación de la Patriot Act que dotaba de mayores poderes de vigilancia y actuación a las agencias de seguridad estadounidenses para luchar contra el terrorismo. Desde esta fecha nos trasladamos a los días 7, 8, 10 y 11 de enero cuando se produce el ataque y un "Duelo nacional y concentraciones espontáneas" según Le Monde, el ataque a la tienda kosher y " $[\ldots]$ la marcha republicana en homenaje a las víctimas de los atentados" según Le Figaro. Finalmente, el endurecimiento del dispositivo antiterrorista culmina este itinerario.

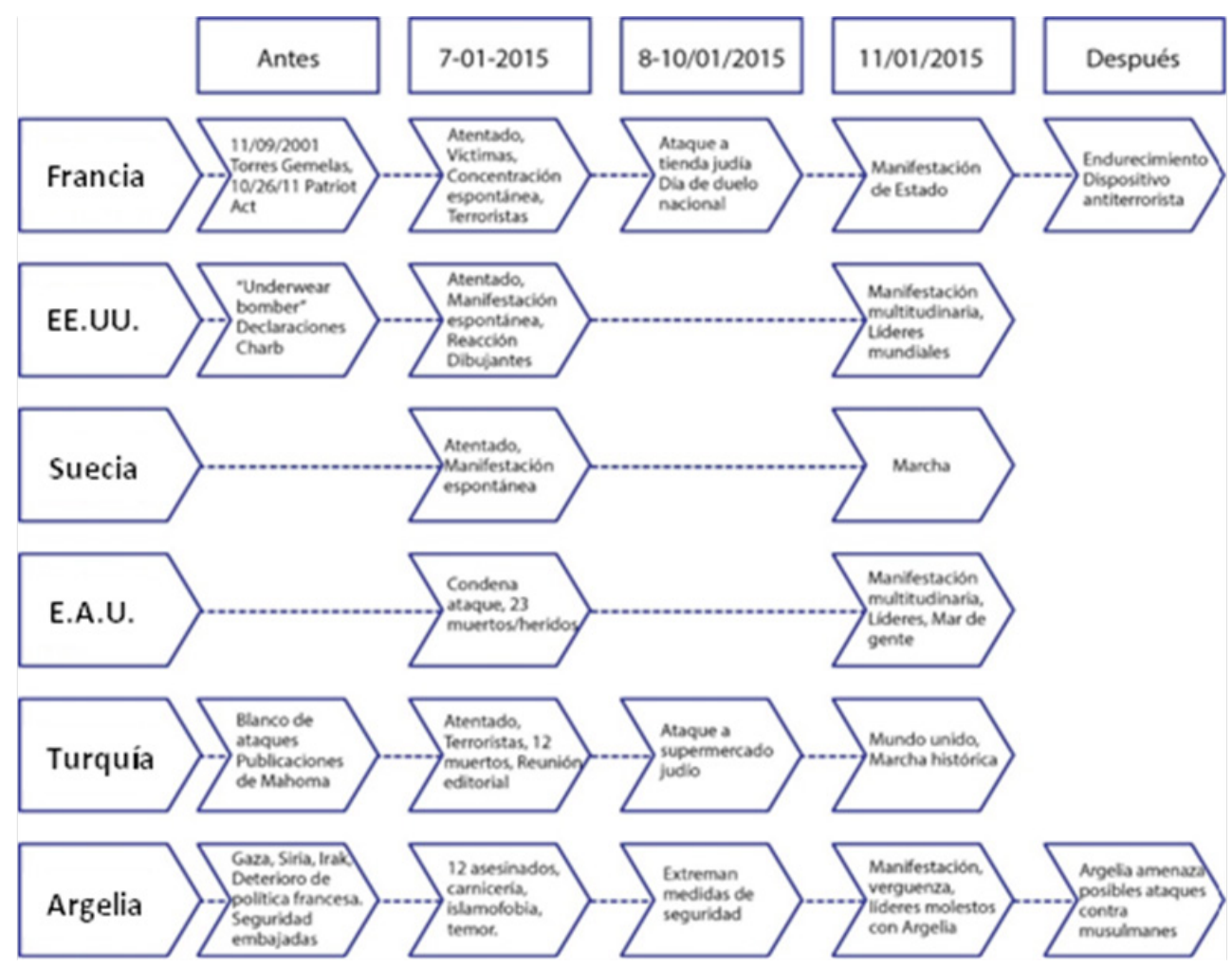

Figura 1. Itinerarios cronológicos en función del país. Elaboración propia.

Las publicaciones estadounidenses comienzan su línea temporal con el Underwear bomber, denominación que recibió un terrorista que pretendía atentar en Detroit el 1 
de junio de 2009. A continuación, el diario USA Today se traslada al año 2012 con las declaraciones del editor Stephane Charbonnier. En este punto, el programa continúa el día en que "El terror golpea Paris" y se sucede la manifestación espontánea según la información de The Wall Street Journal. El itinerario termina con "El mundo se une en Paris" de USA Today.

Suecia y EAU presentan los itinerarios más cortos, centrados en los días 7 y 11 de enero de 2015. Por un lado, Suecia abre su cronología con los titulares del Dagens Nyheter, "Somos un periódico. Estamos de duelo hoy" y la manifestación espontánea posterior. El itinerario termina con "Millones de personas participaron en las marchas contra el terror - y por la libertad de expresión" que publica el diario Aftonbladet. Por otro lado, EAU comienza su línea temporal el día del "(...) ataque armado contra Charlie Hebdo" que publica Al Ittihad y termina la fecha de la manifestación en la que "Los líderes mundiales muestran solidaridad y resistencia” según el diario Kahleej Times.

Turquía tiene el programa más extenso, tras Francia y Argelia, que se asemeja en temporalidad al de Estados Unidos. Su cronología comienza en el año 2006 en el que, según publica Posta, "La revista estaba en el blanco de las organizaciones terroristas extremistas por la publicación de caricaturas del profeta Mahoma". Al igual que los diarios franceses, el próximo acontecimiento es el atentado contra la tienda kosher. El itinerario acaba con los titulares "Que así sea siempre" y el "Mundo unido contra el terror" publicados en Posta y Zaman, respectivamente.

En un sentido completamente opuesto al resto de países, encontramos el itinerario de Argelia que tan sólo coincide en las fechas del atentado y la manifestación. En primer lugar, la publicación Echorouk habla de "Indiferencia por las masacres de Gaza, Irak, Siria y Libia [...]" y titula "Estas son las consecuencias de la deteriorada política francesa". Continúa tratando un aumento de la seguridad en las embajadas de Argelia tras un incremento del terrorismo en el país. Desde este momento se traslada a la "Carnicería en el corazón de París" y a la mejora de la seguridad de las embajadas de Argelia en el exterior por temor a represalias según El Khabar. La cronología finaliza con la manifestación en Paris sobre la que Echorouk publicó: “¡Horror y vergüenza caerá encima de vosotros presidentes árabes!" y con las amenazas de Argelia a Francia, en caso de que haya ataques contra la comunidad musulmana.

La polarización de los itinerarios en dos grupos supone un punto de partida para el análisis del relato narrativo y la elaboración del modelo actancial. Durante la descripción de estos programas cronológicos comprobamos, a través de los fragmentos citados, diversas categorizaciones de los hechos y los personajes involucrados en ellos por parte de las publicaciones de cada país.

\subsubsection{Programa narrativo y modelo actancial}

Los programas narrativos o itinerarios detectados se distribuyen atendiendo a particularidades y similitudes entre países y publicaciones. A partir de estos datos percibimos dos grandes programas opuestos. El primero de ellos es el de Francia, en torno al que se alinea el relato de Estados Unidos, Turquía, Suecia y Emiratos Árabes Unidos. El segundo programa contempla tan sólo el relato de Argelia. Observemos pues, en primer lugar, el modelo actancial que aglutina los relatos del programa narrativo francés: 


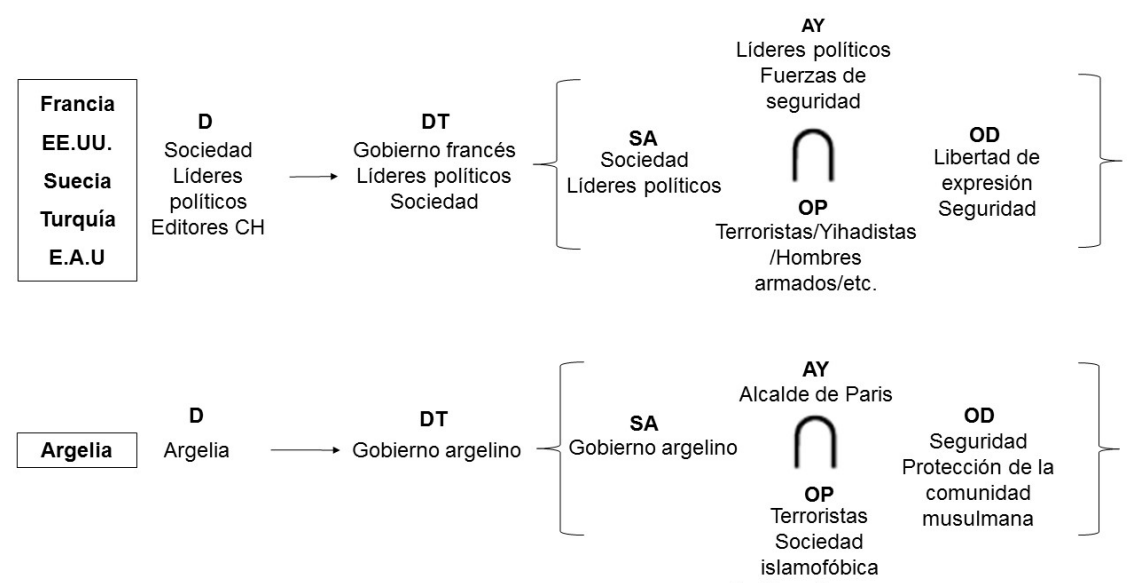

Figura 2. Modelo actancial aplicado a los relatos de Francia, Estados Unidos, Suecia, Turquía, EAU y Argelia. Elaboración propia.

El programa de Francia, creado por Le Monde y Le Figaro, representa a la sociedad francesa y a François Hollande como sujetos de acción (SA) en busca de la unidad tras un ataque terrorista (desajuste). Los líderes mundiales y una suerte de sociedad global se conforman como ayudantes para adquirir valor (competencia) y organizar la manifestación multitudinaria (performance). En este relato, los oponentes (OP) son los terroristas y su objetivo de censura lo que motivó el ataque. Finalmente, llevada a cabo la manifestación, los sujetos reciben como recompensa (sanción) recuperar su derecho a expresarse libremente, que se plasma en la unidad de la sociedad y los líderes políticos.

En esta línea, Estados Unidos presenta a la sociedad francesa como sujeto de acción que reclama seguridad e implicación a su gobierno. La sociedad y los líderes mundiales garantizan, como ayudantes, que esto sea posible. La sociedad francesa organiza la manifestación (performance) para reclamar seguridad y unidad. La recompensa se produce, al igual que en el programa francés, a través de la manifestación multitudinaria.

Los relatos de Suecia y Turquía son muy similares entre sí, ya que expone a la sociedad francesa como sujetos de acción y ente de cambio ante el atentado (desajuste). El objeto aquí es ofrecer resistencia y defender la libertad de expresión ante los terroristas, tomados como oponentes del pasado. La sociedad francesa organiza la manifestación como performance y obtiene el beneficio de una respuesta global contra el ataque. En último lugar, Emiratos Árabes Unidos centró su relato en la sociedad global y la Liga Árabe (SA) como responsables en busca de una solución ante el ataque. Aquí el objeto de deseo se centra en conseguir acuerdos mundiales contra el terrorismo. Para ello, se convoca la manifestación con los líderes (performance) y se obtiene la unidad social y el principio de acuerdo político (sanción).

El programa argelino, creado por los periódicos Echoruk y El Khabar, expone un relato completamente opuesto al del resto de países. En este caso, el objeto de deseo es garantizar la seguridad de la comunidad musulmana (SE) y evitar las represalias de la sociedad occidental. El sujeto de acción de este relato está representado en el Gobierno argelino. En cambio, el Gobierno francés y los go- 
biernos árabes que participan en la manifestación se configuran como oponentes. Francia, por fomentar políticas erróneas para frenar el terrorismo y los países árabes por colaboracionistas en beneficio propio. El único ayudante es el Alcalde de Paris que reclama un "no a la islamofobia". No existe una performance en el relato de los periódicos, pero sí una recompensa para los antisujetos/oponentes: el aumento del terrorismo y más argumentos xenófobos para los partidos conservadores europeos.

Como conclusión, destaca la importante dicotomía que presentan ambos programas: la finalidad de Argelia es mantener seguras sus fronteras y a las comunidades musulmanas, mientras que Francia se centra en reclamar medidas de represalia contra los países relacionados con el terrorismo.

\subsubsection{Perspectivas axiológicas}

Una vez detectados los programas narrativos en torno al ataque de Charlie Hebdo, se identifican los valores asociados a ambos relatos, donde de nuevo subyacen dos esquemas axiológicos divergentes entre los dos bloques de países.

Para su identificación, se realizó un análisis de campos asociativos o contextuales. Se trata de agrupaciones de palabras según su significado y ubicación en el texto de los diarios (Pano, 2011) que permiten desvelar cómo se catalogó el ataque, las emociones, a los hermanos Kouachi, a la comunidad musulmana y las movilizaciones. Esta agrupación puede observarse a continuación en cuatro bloques:

1. Libertad de expresión - Libertad de pensamiento // Terror - Asustados Miedo - Temor - Espíritu de Guerra - Lucha - Amenaza - Condena - Discriminación - Endurecimiento - Enfrentan - Indiferencia - Juzgan - Molestos - Prohibición - Sanciones - Tentación - Vergüenza - Horror - Violencia

2. Víctimas - Asesinados - Heridos - Muertos // Carnicería - Asesinato - Masacre - Brutalidad - Ataque - Atentado - Asalto - Crimen

3. Hombres armados - Sospechosos - Atacantes - Acusados - Criminal - Asesinos - Terroristas - Yihadistas - Extremistas // Mahoma - Profeta - Allahu Akbar - Árabes - Musulmanes - Comunidad Musulmana - Islamofobia

4. Manifestación - Marcha - Congregación - Movimiento - Acto - Concentración - Participantes // Solidaridad - Resistencia - Unidad - Corazón - Apoyo - Colaboración - Defender - Demostrar - Diplomacia - Inocente - Protección - Reconciliación - Revolución - Sentimiento - Duelo

El esquema axiológico que puede extraerse de la narrativa expuesta por Francia y el resto de los países de este grupo muestra el enfoque Valentía (Solidaridad, Resistencia, Protección, Revolución, etc.) vs Terror (Asustados, Temor, Horror, Violencia, etc.), como dos emociones opuestas que enfrenta la sociedad en el discurso textual. Se expone también el enfoque de Libertad de expresión (Libertad de pensamiento) vs Censura (Prohibición, Sanciones, Asesinato, Carnicería, etc.) como valores de pérdida y ganancia. La sociedad y los líderes políticos se manifestaban, en estos relatos, con el objeto de defender la libertad de expresión en todas sus formas y en oposición al mensaje de censura enviado por los hermanos Kouachi. La figura 3 muestra estos dos esquemas axiológicos: 


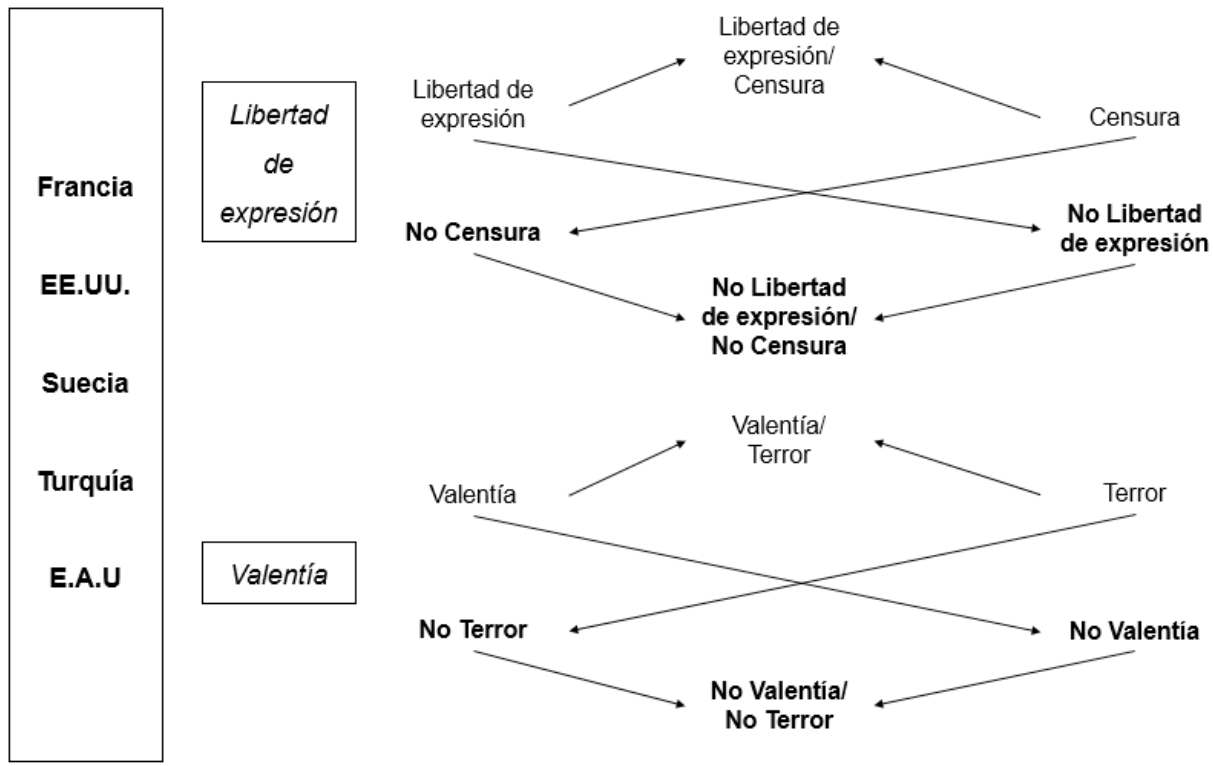

Figura 3. Esquema axiológico Libertad de expresión vs Censura y esquema axiológico Valentía vs Terror. Elaboración propia.

El primer esquema axiológico que presenta la contraposición de los valores $\mathrm{Li}$ bertad de expresión y Censura lleva asociadas las siguientes lecturas:

- Libertad de expresión: toda manifestación contra las pérdidas o daños causados por los ataques terroristas.

- Libertad de expresión/Censura: unión de valores que se produce en el instante del atentado.

- Censura: ausencia de declaraciones, en los diarios, de las comunidades musulmanas francesas involucradas.

- No censura: referencia el valor de las caricaturas que surgieron en las manifestaciones espontaneas tras el ataque.

- No libertad de expresión: muerte de los dibujantes que conlleva una muerte simbólica del valor de libertad de expresión de la República francesa.

- Ni censura/ Ni libertad de expresión: valores que se asocian a las manifestaciones de líderes políticos y comunidades religiosas.

La contraposición de los valores Valentía y Terror que se observa en la figura 3 conlleva las siguientes lecturas:

- Valentía: unión del pueblo francés con los líderes mundiales para hacer frente al ataque terrorista.

- Valentíal Terror: manifestaciones espontaneas que surgieron tras el ataque, cuando aún se temía que se produjese otro de forma inminente.

- Terror: valor que buscaba causar el atentado de los hermanos Kouachi.

- No Terror: resta efectividad al ataque reivindicando la reacción de la población. 
- No valentía: el ataque terrorista contra un medio de comunicación sin protección.

- No valentía/ no terror: valor asociado a los hermanos Kouachi y a su ataque.

Por otro lado, Argelia, a través de sus publicaciones, creó un esquema axiológico diferente a los presentados por Francia y el resto de países de la muestra. Este esquema se mueve entre los valores de Inocencia (Comunidad musulmana, Árabes, Religión, etc.) vs Culpabilidad (Políticas francesas, Terroristas, Presidentes Árabes, etc.) y aglutina los valores del discurso del gobierno de Argelia cuando presenta como inocentes a la comunidad musulmana, francesa y argelina. La culpabilidad se centra en la esfera política y los terroristas. Entre ellos se establece una relación causa-efecto-consecuencia que generó el ataque a Charlie Hebdo. A continuación, se puede observar en la figura 4 la representación de este esquema:
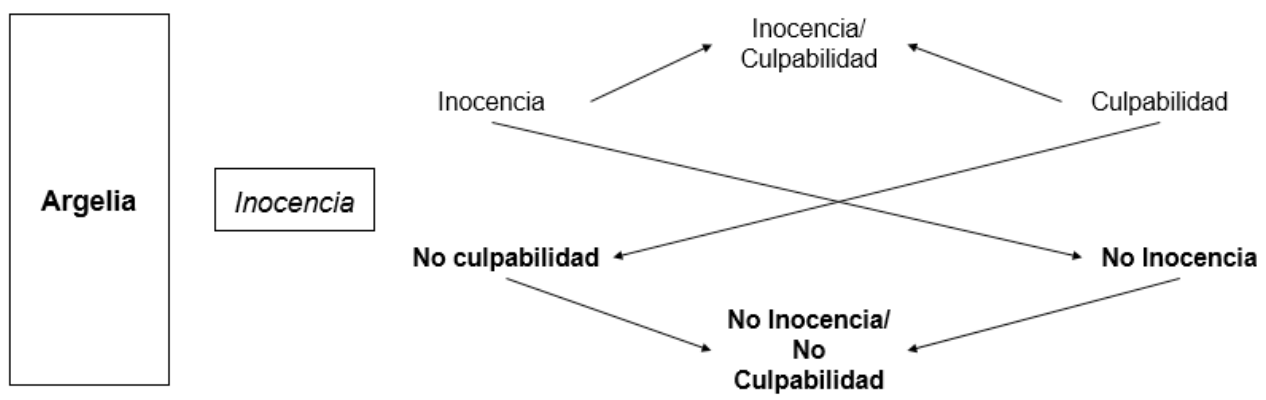

Figura 4. Esquema axiológico de Argelia según sus publicaciones. Elaboración propia.

El esquema argelino que presenta la contraposición entre los valores Inocencia y Culpabilidad tiene asociadas las siguientes lecturas:

- Inocencia: musulmanes practicantes de la comunidad francesa y hermanos Kouachi que se han visto empujados, por su contexto social, a atentar.

- Inocencia/ culpabilidad: la sociedad francesa por sufrir el ataque y por generarlo.

- Culpabilidad: deteriorada política militar y social francesa además de la colaboración con ella de los presidentes árabes.

- No culpabilidad: comunidad musulmana en un sentido global.

- No Inocencia: hermanos Kouachi por realizar el ataque.

\subsection{Aportación metodológica: taxonomía de encuadres narrativos}

Esta aportación metodológica se ha propuesto unificar el análisis semiótico narrativo, de los textos de portada, con el análisis inductivo de encuadres. Se trata de incorporar a la construcción de los modelos narrativos (actancial y axiológico), la localización de los encuadres creados por las publicaciones a través de su cobertura formal y discursiva, con el fin de elaborar una agrupación de los news frames específicos con los que las publicaciones abordaron el ataque a Charlie Hebdo en los dos días de cobertura analizados. 
La clasificación que mostramos a continuación, se compone de siete encuadres narrativos que comparten definiciones y descripciones con los diferentes esquemas desarrollados:

1. Sociedad empoderada: se muestra el conjunto de la sociedad, materializada en la sociedad francesa, participando en actos de manifestación pública en homenaje a las víctimas, luchando por la libertad de expresión, contra el terrorismo y reivindicando su papel de ciudadanía crítica y activa. Representa el relato de una sociedad en acción no violenta contra los ataques.

2. Liderazgo solidario: se expone a los líderes políticos como un colectivo centrado en respaldar el empoderamiento social contra el terrorismo. Superando prejuicios políticos, étnicos y religiosos y con un papel activo en el proceso de duelo. Representa el relato del gobierno ayudante con acciones secundarias de apoyo.

3. Protagonismo gubernamental: se ilustra a la sociedad como ente de cambio y sitúa a los gobiernos nacionales e internacionales como elemento de defensa, lucha y estabilización tras la crisis. Representa al gobierno como una competencia adquirida por la sociedad para enfrentarse a los conflictos externos.

4. Liderazgo culpabilizado: se muestran las consecuencias de una pasividad selectiva de ciertos gobiernos ante otros conflictos bélicos y el fomento de políticas contrarias a la paz. Representa el relato de los líderes mundiales como desajuste, catalizadores del atentado.

5. Víctima política y religiosa: se expone al colectivo musulmán, francés y argelino, como víctimas de las políticas internacionales. Especialmente las políticas francesas postcoloniales y migratorias. Representa el relato de los terroristas y la comunidad musulmana como sujeto de estado que sufre la aplicación de políticas injustas.

6. Símbolo de la libertad: se muestra a los dibujantes y los cuerpos de seguridad fallecidos como un acto de sacrificio por la libertad de expresión. Representa el relato de la muerte como motivación de la sociedad para defender y proteger este valor.

7. Asesinos: se retrata a los hermanos Kouachi como meros terroristas, obviando el contexto (origen francés) y las causas (presión migratoria, desempleo, marginación, etc.). Contempla el relato de un ataque episódico y aislado de cualquier antecedente.

Además de su detección, resultó de especial interés detectar la distribución de los encuadres narrativos en la muestra temporal. A través de un análisis de contenido desarrollamos, en el Gráfico 1, las frecuencias en función de la publicación y el día de análisis: 


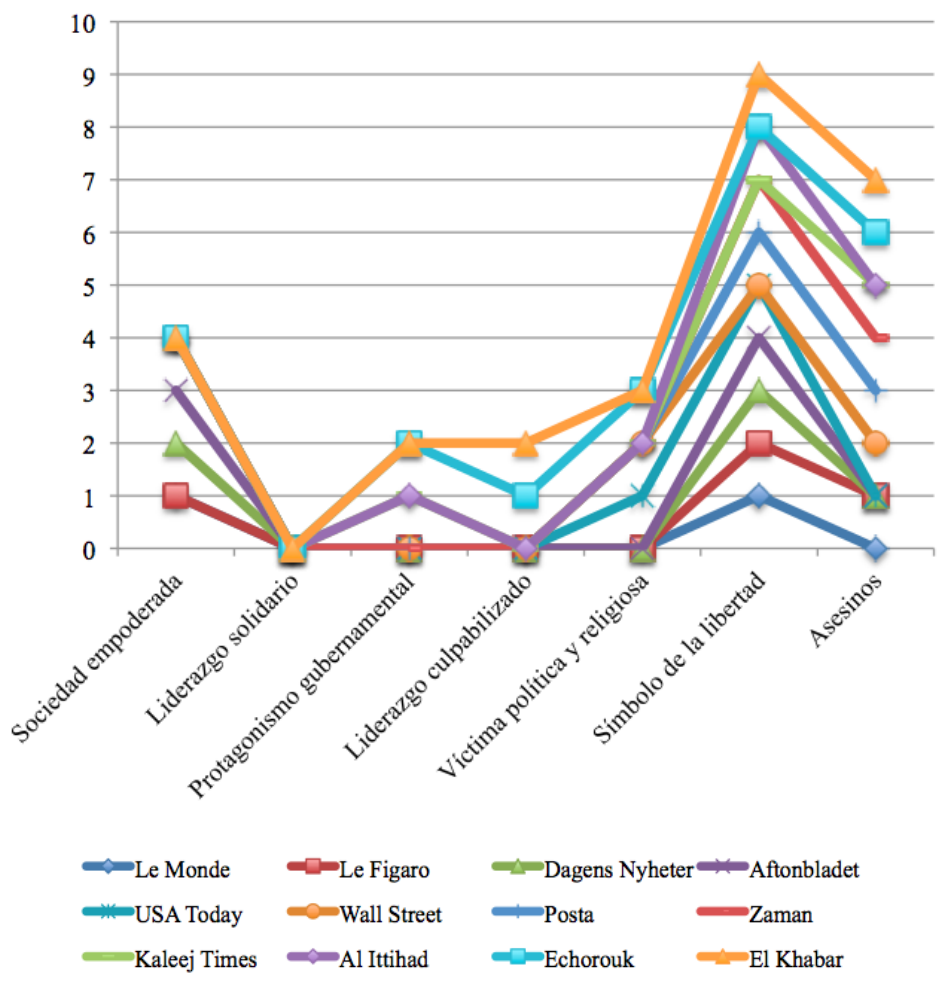

Gráfico 1. Distribución de los encuadres narrativos (frecuencia absoluta) en función de la publicación y el día. Elaboración propia.

Este gráfico representa una distribución con criterios de temporalidad de los encuadres narrativos. La mayoría de publicaciones coinciden, en frecuencia, en los encuadres de Sociedad empoderada, Símbolo de la libertad y Asesinos el día 8 de enero de 2015. Echorouk y El Khabar destacan por emplear también este día los encuadres de Protagonismo gubernamental, Liderazgo culpabilizado y Víctima política y religiosa. Por otra parte, el día 12 de enero de 2015 las publicaciones coinciden en dar mayor representación a los encuadres Sociedad empoderada y Símbolo de la libertad. De forma individual, USA Today, Wall Street Journal o Posta emplean el encuadre Liderazgo solidario. Echorouk y El Khabar recurren de nuevo a los encuadres de Liderazgo culpabilizado y Protagonismo gubernamental incidiendo en la división entre el bloque de Argelia y el bloque alineado con Francia.

En definitiva, existen paralelismos entre los programas narrativos y la utilización más o menos frecuente de los encuadres detectados. Esto es lógico teniendo en cuenta que surgen de un análisis que incluye los programas narrativos. El resultado más relevante es su distribución temporal, ya que muestra el dinamismo o la estaticidad de las publicaciones al aplicar unos encuadres u otros. 


\section{Discusión y conclusión}

Los resultados de esta investigación presentan dos claras tendencias en la cobertura mediática de los atentados según el país de la publicación. Una construcción narrativa y una cobertura textual y visual centrada en Francia y seguida por Estados Unidos, Turquía, Suecia y Emiratos Árabes Unidos y una construcción sólo representada por Argelia.

Estos resultados son consistentes con los hallados por Wolska-Zogata (2015) que resume esta polarización en dos macro-frames de la cobertura occidental de los ataques: "fight against terror" y "defending the freedom of the press". Gerhads y Schafer (2013) localizan también la creación de dos bloques informativos con una marcada contraposición de ideales entre los medios Al Jazeera y CNN. Estos canales de televisión, al igual que las publicaciones de Francia y Argelia, marcaron tendencia en cuanto a la construcción de narrativas compartidas por el resto de los informativos de la muestra. Este estudio hace evidente una contraposición de valores entre Occidente y Oriente que se perpetúa a través de sus canales informativos. El contraste del presente trabajo sobre prensa escrita con el estudio de Gerhads y Schafer aporta datos de que la polarización no varía según el medio de difusión.

En definitiva, esta investigación añade evidencias a los resultados de estudios previos y aporta la novedad de aplicar una metodología mixta que profundiza en la cobertura mediática a través de la agenda-setting, la semiótica narrativa y el framing. Consideramos que futuras investigaciones deben ampliar la muestra de países orientales y de sistemas mediáticos como el latinoamericano o el ruso en los que los medios de comunicación siguen otras dinámicas informativas (Hallin y Mancini, 2011). Estas dinámicas, en cuanto al tratamiento de sucesos y crisis, resultan de gran valor en estudios comparativos para el conocimiento de realidades culturales normalmente obviadas en las investigaciones académicas.

Durante la redacción de este artículo, tuvo lugar el 13 de noviembre a las $21.30 \mathrm{~h}$ en la Sala Bataclan de Paris un nuevo atentado. Al igual que sucedió con el ataque contra Charlie Hebdo, se ha producido una intensificación en la cobertura mediática y una reacción masiva de la sociedad, en especial a través de redes sociales. Este nuevo ataque deberá ser considerado para un futuro estudio comparativo, con la finalidad de detectar si existen recurrencias en la cobertura mediática en cuanto a elementos formales, narrativos y de encuadre.

\section{Referencias bibliográficas}

Amara, Mahfoud (2013): "Sport, Islam, and Muslims in Europe: in between or on the Margin?". Religions, 4 (4), 644-656.

DOI: 10.3390/rel4040644. http://www.mdpi.com/2077-1444/4/4/644. [Consulta: 10 de marzo de 2015]

Ariyanto, Amarina; Hornsey, Matthew; Morton, Thomas; and Gallois, Cindy (2008): "Media bias during extreme intergroup conflict: the naming bias in reports of religious violence in Indonesia". Asian Journal of Communication, 18 (1), 16-31.

DOI: $10.1080 / 01292980701823740$.

Cáceres, María Dolores (2011): "La construcción social de la realidad: el papel de los profesionales en el establecimiento de la agenda temática". Estudios sobre el mensaje 
Periodístico, 17 (2), 303-324. http://eprints.ucm.es/22457/1/36868.pdf. [Consulta: 16 de marzo de 2015]. Madrid, Ediciones Complutense.

Chavero, Palmira; González, Juan Jesús; Bouza, Fermín; Castromil, Antón; y Rodríguez, Raquel (2013): "La mediatización de la agenda política: la discusión del pacto social como conflicto de agendas, 2009-2011". Revista Latina de Comunicación Social, 68, 639-655. http://www.revistalatinacs.org/068/paper/994_Complutense/28_Palmira.html. [Consulta: 12 de marzo de 2015]. DOI: 10.4185/RLCS-2013-994.

De Vreese, Claes H.; Peter, J; and Semetko, Holly (2001): "Framing Politics at the Launch of the Euro: A Cross-National Comparative Study of Frames in the News". Political Communication, 18 (2), 107-122. DOI: 10.1080/105846001750322934.

Dolezal, Martin; Helbling, Marc; and Hutter, Swen (2010): "Debating Islam in Austria, Germany and Switzerland: Ethnic Citizenship, Church-State Relations and Right-Wing Populism". West European Politics, 33 (2), 171-190.

DOI: $10.1080 / 01402380903538773$.

Entman, Robert (1991): "Framing U.S. coverage of international news: contrasts in narratives of the KAL and Iran Air incidents". Journal of Communication, 4 (41), 6-27. DOI: 10.1111/j.1460-2466.1991.tb02328.x.

Floch, Jean-Marie (1993): Semiótica, marketing y comunicación. Barcelona, Paidós.

García Marín, Javier (2012): "Encuadres, conflictos y efectos de agenda". Zer-Revista de Estudios de Comunicación, 16, (31), 167-181.

http://www.ehu.eus/ojs/index.php/Zer/article/view/4835/4705. [Consulta: 18 de febrero de 2015]

Gerhards, Jurgen \& Schafer, Mike (2013): "International terrorism, domestic coverage? How terrorist attacks are presented in the news of CNN, Al Jazeera, the BBC, and ARD". International Communication Gazette, 78 (1), 3-26.

DOI: $10.1177 / 1748048513504158$.

Goffman, Erving (1974): Frame Analysis. Cambridge, Harvard University Press.

Greimas, Algirdes Julien (2007): Semántica estructural. Investigación metodológica. Madrid, Gredos.

Greimas, Algirdas Julien y Courtés, Joseph (1982): Semiótica. Diccionario razonado de la teoría del lenguaje. Madrid, Gredos.

Hallin, Daniel \& Mancini, Paolo (eds.) (2011): “Comparing media systems beyond the Western world". Cambridge, Cambridge University Press.

Kassed, Hanaa Kadum \& Mustaffa, Che Su (2014): “Agenda Setting of Iraq Image in Malaysian English Newspaper”. Asian Social Science, 11 (2), 225-237.

DOI: http://dx.doi.org/10.5539/ass.v11n2p225.

Konstantinidou, Christina (2008): "The spectacle of suffering and death: the photographic representation of war in Greek newspapers". Visual Communication, 7, (2), 143-169. DOI: $10.1177 / 1470357208088756$.

Krippendorff, Klaus \& Bock, Mary Angela (2009): The content analysis reader. London, Sage.

Lee, Seow Ting; Maslog, Crispin; and Kim, Hun Shik (2006): “Asian Conflicts and the Iraq War A Comparative Framing Analysis". International Communication Gazette, 68 (6), 499-518. DOI: 10.1177/1748048506068727.

McCombs, Maxwell (2004): Setting the Agenda. Cambridge, Polity Press.

Pano Alamán, Ana (2011): "El término "inmigrantes" en los titulares de prensa: entre interculturalidad e hibridación”. Confluenze: Rivista di Studi Iberoamericani, 3 (1), 188207. DOI: 10.6092/issn.2036-0967/2209. 
Penalva, Clemente y Mateo, Miguel Ángel. (2000): “Análisis narrativo y guerra. La cobertura del diario El País sobre el conflicto de Kosovo". Revista Internacional de Sociología, 26, 187-210. http://hdl.handle.net/10045/2470 [Consulta: 10 de marzo de $2015]$.

Reese, Stephen (2010): "Finding frames in a web of culture: The case of the War on Terror". En D'angelo, Paul y Kuypers, Jim A (eds.): Doing news framing analysis: Empirical and theoretical perspectives, pp. 17-43. New York, Routledge.

Reese, Stephen \& Lewis, Seth (2009): "Framing the War on Terror The internalization of policy in the US press". Journalism, 10 (6), 777-797.

DOI: $10.1177 / 1464884909344480$.

Riffe, Daniel; Lacy, Stephen; and Fico, Frederick (2014): Ananlyzing Media Messages. New York, Routledge

Rodrigo Alsina, Miquel (2004): “¿Pueden los periodistas ser no etnocéntricos?” En Contreras, Fernando y Sierra, Francisco (coords.): Culturas de guerra: medios de información y violencia simbólica, pp. 239-254. Valencia, Universitat de València.

Rogel, Diana \& Cabrera, Ketty (1996): "Principales actores en el establecimiento de la agenda setting". Aularia, 237-240. En:

http://www.aularia.org/ContadorArticulo.php?idart=110. [Consulta: 15 de marzo de 2015]

Ruíz Collantes, Xavier; Obradors, Matilde; Pujadas, Eva; Ferres, Joan; y Pérez Latorre, Oliver (2011): "Qualitative-quantitative analysis of narrative structures: the narrative roles of immigrants in Spanish television series”. Semiótica, (184), 99-121.

DOI: 10.1515/semi.2011.024.

Schwalbe, Carol \& Dougherty, Shannon (2015): "Visual coverage of the 2006 Lebanon War: Framing conflict in three US news magazines". Media, War \& Conflict, pp. 1-22.

DOI:10.1177/1750635215571204.

Smith, Kenneth; Moriarty, Sandra; Barbatsis, Gretchen; and Kenney, Keith (eds., 2005): Handbook of visual communication: Theory, methods, and media. London, LEA

Tankard, James (2001): The empirical approach to the study of media framing. New York, Erlbaum.

Torregrosa, Juan Francisco (2010): "Modelos para el análisis documental de la fotografía". Documentación de las Ciencias de la Información, 33, 329-342. http://revistas.ucm.es/index.php/DCIN/article/view/DCIN1010110329A/18753. [Consulta: 20 de febrero de 2015]

Tuchman, Gaye (1978): Making News. A Study of the Construction of Reality. New York, Free Press.

Visa, Mariona (2012): “Una metodología sociológica y narrativa para el análisis de relatos fotográficos". Estudios sobre el mensaje periodístico, 18, (vol. Extra, noviembre), 929939. http://revistas.ucm.es/index.php/ESMP/article/view/40971/39222. [Consulta: 20 de febrero de 2015]. Madrid, Ediciones Complutense.

Wells, Karen (2007): "Narratives of liberation and narratives of innocent suffering: the rhetorical uses of images of Iraqi children in the British press". Visual Communication, 6 (1), 55-71. DOI: 10.1177/1470357207071465.

Wolska-Zogata, Irena (2015): "The Story of Charlie Hebdo : An Analysis of European and American Newspapers". Mediterranean Journal of Social Sciences, 6 (2), 353-362. http://www.mcser.org/journal/index.php/mjss/article/viewFile/6201/5946 [Consulta: 20 de septiembre de 2015]. DOI: 10.5901/mjss.2015.v6n2s5p353.

Yin, Robert K (2013): Case study research: Design and methods. London, Sage. 


\section{Conflictos de interés}

Todos los autores de este artículo declaran que no existe ningún conflicto de interés político y/o religioso que influya los resultados obtenidos en esta investigación.

\section{Agradecimientos}

Esta investigación ha sido posible gracias a la colaboración de Maria Sirun, Seda Atabay, Johanna Svensson y Elena Costa en la traducción de los periódicos Echorouk, El Khabar, Posta, Zaman, Dagens Nhyheter, Aftonbladet, Le Monde y Le Figaro respectivamente.

Pablo Gómez-Domínguez es Investigador predoctoral del Departamento de Comunicación. Miembro del grupo de investigación UNICA. Colaborador del Observatorio de la Producción Audiovisual de Cataluña (OPA). Universitat Pompeu Fabra.

Gabriel Candelaria Rivera es Doctorando de la Universidad de Puerto Rico.

Oliver Pérez Latorre es Profesor doctor del Departamento de Comunicación. Miembro del grupo de investigación UNICA. Universitat Pompeu Fabra.

Lorena Gómez-Puertas es Profesora Lectora del Departamento de Comunicación. Miembro del grupo de investigación UNICA. Universitat Pompeu Fabra. 